\title{
Mapas fotográficos do Google:
}

\section{Arte contemporânea e as perturbações visuais da mirada aérea}

\section{Google photo maps:}

\section{Contemporary art and aerial photography visual disturbances}

\section{Por Grécia Falcão}

\section{Introdução à proposta}

Neste paper, proponho um encontro com fotografias aéreas, mais especificamente com imagens fotográficas produzidas a partir de aeronaves e satélites que compõem o popular sistema de mapeamento geográfico do Google: o Google Maps. Minha proposta consiste em uma reflexão sobre o advento da mirada aérea na esfera da arte, a partir de hipóteses sobre uma possível "zona de contato" entre mimese, abstração e representação diante das produções visuais da arte contemporânea. Para mobilizar tais questões, acredito ser necessário estabelecer um olhar aguçado para as práticas artísticas da atualidade, circunstanciadas em uma realidade social que sugere a multiplicação dos fluxos de produção e de circulação de imagens diante das atuais tecnologias da comunicação. Diante disto, tomo por referência a obra de Mishka Henner: artista belga que utiliza, como fonte de pesquisa para suas obras, os registros fotográficos que estão disponíveis online, de forma que este percurso reflexivo será desenvolvido a partir da descrição de duas séries fotográficas do artista.

O conteúdo visual que circula na web é a fonte de inspiração e o material empírico para os trabalhos de Mishka Henner: a exemplo de fotografias que trafegam pela Internet, além de vídeos do YouTube, mapas digitais do levantamento geológico dos EUA, textos de e-mails e algoritmos que estão em domínio público na web. No entanto, boa parte de suas obras baseia-se na apropriação de imagens fotográficas disponíveis nos serviços de pesquisa e de visualização de 
mapas desenvolvidos pela empresa norte-americana Google. Em pelo menos oito séries fotográficas $^{1}$, o artista reutiliza as fotografias que foram disponibilizadas no Google Maps para registro visual da arquitetura e da topografia planetária. Em breves palavras, o Google Maps é o sistema de mapas online mais utilizado no mundo, disponível para uso gratuito na Internet. Tratase de um Sistema de Informação Geográfica (SIG): termo técnico que designa tipos de softwares que fornecem dados cartográficos para o usuário, incluindo a monitorização de seus trajetos por meio de GPS, além de outros serviços para auxílio de deslocamento nas cidades.

Estão associados aos SIGs do Google os serviços Google Earth e Google Street View, que fornecem o mapeamento geográfico a partir de fotografias aéreas e de fotografias registradas ao nível do solo. O trabalho artístico de Mishka Henner é dedicado, principalmente, ao reuso das imagens fotográficas visíveis nesses softwares, cuja finalidade é disponibilizar um mapa online que traga a sensação de realidade aumentada (VR - "Virtual Reality") para o usuário. Ou seja, nos aplicativos Google Earth e Google Street View, o usuário é capaz de interagir com sequências fotográficas que estão "ligadas" umas às outras a partir de dados geoespaciais. Disso resulta o surgimento de interfaces que tratam de simular um tour virtual por meio de fotografias digitais, semelhante ao passeio ao vivo por locais de interesse previamente escolhidos no mapa online. A atualização destas fotografias nas SIGs do Google é feita de tempos em tempos, seja pelos próprios usuários do serviço, que fotografam as ruas de suas cidades para inserção no aplicativo Google Street View, seja a partir de parcerias da empresa Google com a NASA, agência norte-americana de exploração espacial, que dispõe das mais novas tecnologias para captação de fotografias por aeronaves e satélites, passíveis de serem utilizadas para compor os aplicativos Google Moon, Google Mars e Google Earth, que, respectivamente, criam réplicas da superfície da Lua, do planeta Marte e do planeta Terra.

A obra de Mishka Henner trata, em larga medida, da seleção, edição e montagem destas "fotografias-mapa" em museus, galerias e demais espaços dedicados à prospecção da arte contemporânea. O artista navega por meio da simulação visual dos mapas Google, e recorta enquadramentos fotográficos disponíveis no Sistema de Informação Geográfica mais popular da Internet. Suas séries fotográficas agem, fundamentalmente, como forma de repensar a condição

\footnotetext{
1 Trata-se das séries fotográficas: "Fifty-one US Military Outposts" (2010); "Dutch Landscapes" (2011); 'Libyan Oil Fields" (2011); "Eighteen Pumpjacks" (2012); “Fields" (2012-13); “Feedlots" (2012-13); "No Man's Land" (2011-13); e "Turbines" (2017-18) que, juntas, reúnem centenas de fotografias de paisagem capturadas a partir da plataforma de mapas Google.
} 
fugaz e massiva da fotografia digital no ambiente online, o que - de diferentes maneiras - passa a questionar o uso do dispositivo fotográfico em seus significados breves, quando as formas de apreensão da imagem parecem restritas à sua narrativa enquanto mimese: "espelho do real".

$\mathrm{Na}$ interface Google Earth, por exemplo, as fotografias aéreas de nosso planeta foram precisamente "coladas", com o auxílio de cálculos matemáticos e dos parâmetros referenciais da ciência cartográfica (latitude, longitude e altura), sobre um modelo esférico que simula o formato da geografia terrestre. Desta forma, as fotografias registradas do alto a partir de aeronaves e satélites e produzidas em alta resolução passam a funcionar como um mapa que, por precisão ótica e cartográfica, simula o formato total da superfície da Terra. Esse software de geolocalização utiliza a técnica fotográfica para a criação de uma narrativa visual que preza pela verossimilhança, em outras palavras, pela "melhor" imitação do real e "mais fiel" representação possível do espaço geográfico.

Isso aponta para uma noção de fotografia de paisagem a qual este artigo pretende confrontar. Por mais "naturalizada" que seja a apreensão dessas fotografias de mapeamento aéreo, no que se refere ao espontâneo reconhecimento pelo espectador das coisas ali representadas montanhas, florestas, ruas, pessoas, animais, objetos etc. -, o que há, nessas imagens fotográficas, são artifícios técnicos muito bem assimilados e até mesmo "incorporados"2 ao sistema perceptivo humano. É o que demonstra Anne Cauquelin (2007), no que tange à sua análise sobre o surgimento da noção de paisagem na História da Arte: um dos gêneros tradicionais da pintura, assim como o retrato e a natureza-morta. Para a filósofa, o conceito de paisagem remonta às diversas formalizações técnicas que, desde o Renascimento (séculos XIV-XVI), tratavam de tentar "equiparar" a experiência da natureza (o mundo das coisas) ao espaço representado na tela bidimensional da pintura. Para atingir tamanha verossimilhança entre "mundo" e "imagem", os pintores clássicos dependiam de estudos matemáticos sobre a perspectiva, e de certo domínio das leis da óptica: conhecimento que, a partir do século XIX, parece ter sido transferido para as formas de uso automático do aparelho fotográfico com rápida captação e revelação de imagens.

\footnotetext{
${ }^{2}$ Vide os atuais softwares de mapeamento geográfico, como o Google Maps, e suas formas de uso em "tempo real". Por exemplo, hoje o sujeito caminha pelas ruas da cidade enquanto volta seu olhar para a tela do smartphone para checar seu posicionamento no mapa por meio de dados de GPS. Cria-se, nesse caso, uma coreografia quase "simbiótica" entre corpo humano e aparato técnico (tela do smartphone) de forma a sustentar seu rápido percurso pela cidade até o local de interesse.
} 


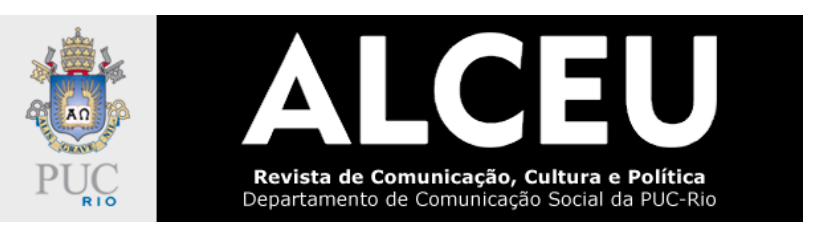

Desde o classicismo até os dias atuais, a camada sociotécnica que subjaz as "maneiras de fazer" das imagens realistas parece ter sido silenciada ou, ao menos, pouco discutida. Em suma, Cauquelin mostra que o surgimento do conceito de paisagem na esfera da arte envolve componentes sociais, circunstanciados no contexto histórico e nas propostas científicas do Renascimento; e técnicos, a exemplo do corrente uso de lentes ópticas e cálculos geométricos nas pinturas clássicas. É algo, portanto, que impede certa visão purista do termo "paisagem" associado ao imaginário de natureza ou "imagem da natureza", que representa de forma "neutra" e "transparente" do ambiente vivido.

De toda forma, uma fotografia de paisagem de cunho realista provoca tamanho efeito de verossimilhança que o espectador é levado a crer que ali enxerga o mundo "de verdade", ainda mais se esta imagem fotográfica tem função prática baseada no uso cartográfico das empresas Google. Contudo, um choque óptico-perceptivo surge quando tais fotografias, que retratam o real, levam o espectador à visão abstrata deste. Na obra de Mishka Henner, a imagem parece funcionar como esse dispositivo de tensões entre o polo comunicável das fotografias, referente à correspondência visual imediata para uso instrumental do mapa online, e abstracional. Trato, neste caso, de construções narrativas que tocam na noção tradicional de paisagem fundamentada pelos ditames da História da Arte, mas que abrem a imagem fotográfica para outras formas de reconhecer e conceber o conceito. Em linhas gerais, este artigo é reflexo do esforço de amplitude do referido tema - a fotografia de paisagem -, e dedica-se, justamente, a desenvolver o conceito a partir da arte contemporânea e das tecnologias da comunicação.

\section{O caso das séries fotográficas "Feedlots" e "The Fields"}

Trago em questão duas séries fotográficas, chamadas "Feedlots" ("Confinamentos", tradução nossa) e "The Fields" ("Os Campos", tradução nossa). Ambas as obras resultam do reaproveitamento das fotografias aéreas disponibilizadas na web por meio dos sistemas de mapas do Google. O projeto "Feedlots" documenta as geografias esculpidas pela indústria da carne norteamericana; e a série fotográfica "The Fields" captura as vistas aéreas dos campos de extração de petróleo nos EUA. As obras são compostas, portanto, de registros fotográficos que documentam os dois maiores motores da economia dos Estados Unidos - a carne bovina e o petróleo - e aguçam nosso olhar para as práticas industriais e para a degradação ambiental do planeta. 


\section{ALCEU

Estas produções fotográficas foram criadas em 2013 e selecionadas para a quinta edição do Prix Pictet, o prêmio global em fotografia e sustentabilidade, que reuniu fotógrafos contemporâneos com trabalhos direcionados para o tema: consumo. A premiação, por sua vez, resultou em uma mostra coletiva que ocorreu em 2014 no Victoria and Albert Museum em Londres, Inglaterra. Lá, junto a dez outros fotógrafos, que também foram indicados ao Prix Pictet daquele ano (Adam Bartos, Motoyuki Daifu, Rineke Dijkstra, Hong Hao, Juan Fernando Herrán, Boris Mikhailov, Abraham Oghobase, Michael Schmidt, Allan Sekula, e Laurie Simmons), Mishka Henner exibiu duas impressões fotográficas, lado a lado, e é a partir delas que se começa esta análise (fig. 1).

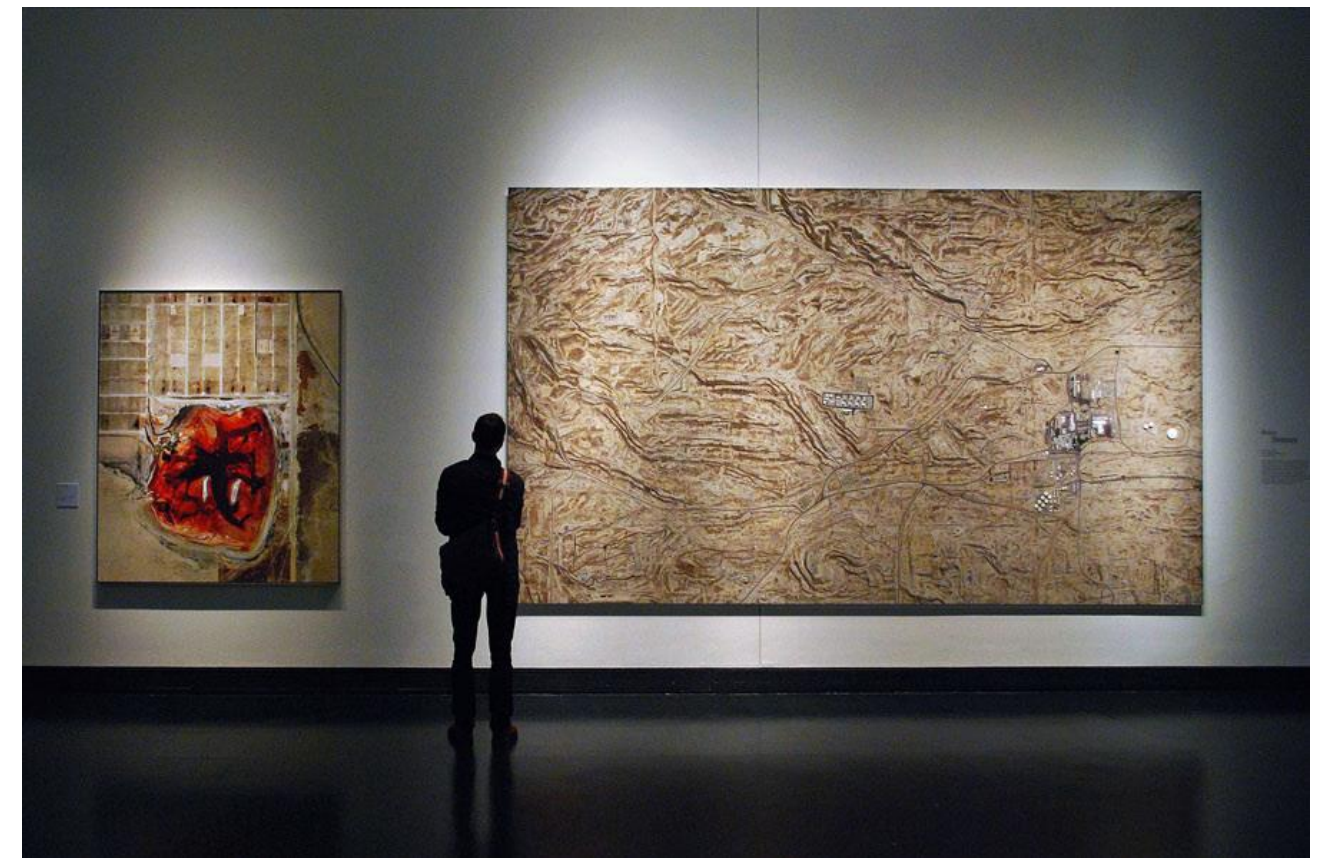

Figura 1 - Coronado Feeders (série: Feedlots) / Kern River (série: The Fields) Mishka Henner, 2013. Exibição Beff and Oil - Victoria and Albert Museum - maio a junho de 2014.

A primeira fotografia refere-se à série "Feedlots", na qual Henner se dedica a capturar diversas tomadas aéreas de fazendas de gado de corte no interior dos Estados Unidos. A primeira foto mostra a fazenda Coronado Feeders, uma propriedade localizada em Dalhart, no estado do Texas, que tem capacidade de confinamento de até 60.000 bovinos (GEAR, 2016). O que chama atenção, nessa fotografia, é o grande borrão vermelho que aparece no centro da imagem. Este é o canal de escoamento, que armazena e transporta os resíduos de animais pós-abate. Uma piscina vermelha de sangue toma conta dos vários hectares da fazenda e reúne os destroços de animais produzidos para consumo. Trata-se de um poço que está conectado às baias de confinamento que organizam, proporcionalmente, os milhares de cabeças de gado que a fazenda Coronado Feeders 
suporta. Em breves palavras, ao olhar essa fotografia, o espectador encara uma paisagem fabril, onde a natureza é regulada para intensificar o rendimento da fabricação da carne bovina.

Ao lado dessa foto, Mishka Henner apresenta uma mirada aérea que faz parte de outro projeto fotográfico do artista. Na série "The Fields", Henner recorta dos mapas Google os registros fotográficos que retratam os campos de petróleo norte-americanos com suas extensas redes de produção e de distribuição do combustível. No Victoria and Albert Museum, por exemplo, o artista exibiu uma fotografia que retrata o Kern River Oil Field: um campo petrolífero de 115 anos localizado no condado de Kern, no estado da Califórnia, EUA. A fotografia, impressa em larga escala, aponta para a imensidão desta paisagem composta por milhares de bombas de feixe que ocupam todos os cantos do deserto no Vale Central da Califórnia (ONISH, 2014) ${ }^{3}$.

Henner buscou por essas vistas aéreas por meio dos softwares de mapeamento geográfico do Google, que disponibilizam publicamente fotografias da superfície terrestre registradas a partir de aeronaves e satélites. Essas séries fotográficas são, portanto, o resultado desse "garimpo" online, que conjuga a análise cartográfica com dados sobre a produção energética e agropecuária dos EUA. Apesar de fazerem parte de projetos fotográficos diferentes ("Feedlots" e "The Fields"), para Henner os dois assuntos (carne e petróleo) estão intimamente ligados, e não apenas visualmente (HENNER apud DAVIES, 2014). A indústria agropecuária, por exemplo, se inicia pelo consumo do milho, alimento fornecido para o gado. Já as grandes quantidades de milho são produzidas a partir de uma grande quantidade de fertilizantes, que, por sua vez, impulsionam as vendas globais da indústria do petróleo. Pois bem, no Victoria and Albert Museum, a fotografia de Coronado Feeders e de Kern River Oil Field estão lado a lado, e apontam para operações de indústrias que se sustentam, economicamente, uma a outra.

O objetivo, agora, é analisar o jogo de sentido empregado pelas fotografias de "Feedlots" e "The Fields", atentando para a maneira como o "olhar distanciado" - o ponto de vista aéreo - pode se configurar como uma maneira de desestabilizar a ideia de paisagem (pictórica ou fotográfica) como imagem que "melhor" representa o espaço; ou seja, imagem que se configura simbolicamente como forma eficaz para a descrição do ambiente. A hipótese é que Mishka Henner constrói, nessas

\footnotetext{
3 "The 115-year-old Kern River oil field unfolds into the horizon, thousands of bobbing pumpjacks seemingly occupying every corner of a desert landscape here in California's Central Valley. A contributor to the state's original oil boom, it is still going strong as the nation's fifth-largest oil field, yielding 70,000 barrels a day" (ONISH, 2014, s/p).
} 


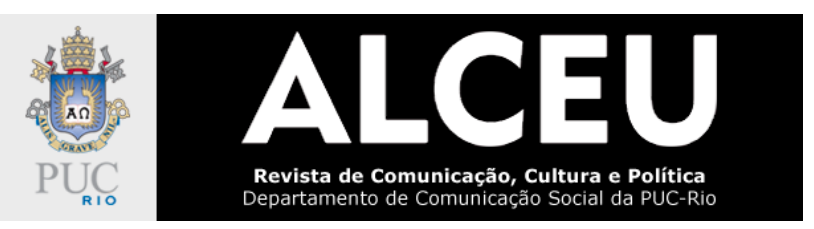

séries fotográficas, uma curiosa narrativa visual que visa "confundir" o espectador para pôr em tensão o caráter verossímil da fotografia de paisagem.

\section{Entre a mimese e a abstração: perturbações visuais da mirada aérea}

Na mirada aérea dos satélites, estamos tão longe da superfície terrestre que a fotografia de paisagem, muitas vezes, se torna um "todo" constituído por linhas, manchas e pontos. A vista de pássaro (bird's eye view) é, historicamente, o método mais utilizado para descoberta e monitoramento de um território. Mas, devido à distância e às variadas angulações do registro fotográfico, essa forma de documentação denota "indícios de abstração", algo que Dubois já havia percebido em certas fotografias de Duchamp, e nos trabalhos de pintura e nas fotografias aéreas de Malevitch (DUBOIS, 2011). Nas fotografias feitas do alto, por meio de drones, aviões ou satélites - que fornecem fotos para os mais populares softwares de geomapeamento online -, a face da Terra mostra cenários próximos à distorção visual. São imagens "sem horizonte, nem profundidade, sem buracos, nem saliências. [...] São achatadas, geometrizadas, "abstratizadas"”' (DUBOIS, 2011, p. 268). Ao contrário das vistas tomadas do solo, ou seja, da representação do espaço herdada da visão monocular clássica, em que o sujeito se posiciona de pé (de frente para o objeto) e fabrica paisagens em desenhos, pinturas, fotografias, buscando um só ângulo. Trata-se de um eixo preciso (ortogonal), que permite visualizar a linha do horizonte e criar a ilusão ótica das regras em perspectiva.

Mas o homem, cada vez mais, se solta do chão e flutua por angulações variadas por meio do ponto de vista aéreo e do anti-aéreo. Assim, surgem novas maneiras de modelizar cores, luzes, sombras e formas na hora de representar o espaço. Nesses termos, a fotografia de paisagem que preza pela documentação do "real" pode, invariavelmente, tender em direção às composições experimentais - como no caso dos registros do fotógrafo norte-americano William A. Garnett, que capturava, do alto de um avião, os alinhamentos precisos das construções de casas no estado da Califórnia, EUA ("Finished Housing, Lakewood California", 1950). O fotógrafo trabalhava com fotografia em preto e branco e com filmes de diferentes formatos, e foi pela mirada aérea que, nos anos 50, Garnett construiu fotografias de paisagens repletas de geometrias retilíneas e curvas. Sua obra mostra a repetição inquietante de contornos precisos que são, neste caso, os vestígios da arquitetura urbana e da topografia da Terra. 


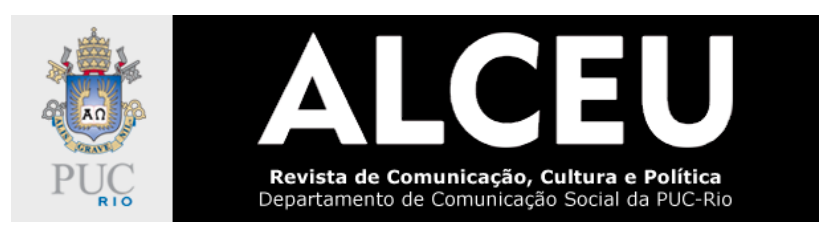

Em suma, é bem possível que, ao registrar determinado assunto "do alto", as imagens fotográficas se distanciem de suas possibilidades representativas (DUBOIS, 2011). Em outras palavras, é provável que, pelo efeito do giro e da distância, a verossimilhança do documento se "desfaça" e crie um composto abstrato de quadrados, círculos, curvas e retas difícil de ser decifrado em seus pormenores pelo olhar do espectador. Diria, contudo, que, na arte de Mishka Henner, as vistas aéreas de "Feedlots" e "The Fields" foram "re-fotografadas" de tão longe que o observador, invariavelmente, se perde pela distância. A fotografia se apresenta como uma forma sintética composta por cores, traços e geometrias. E não há como distinguir, ao certo, o conjunto de objetos e seres que compõem a minúcia de cada cenário.

É por isso que outra faceta igualmente importante desses trabalhos é a ampliação fotográfica. Se, por um lado, a documentação aérea cria formas que beiram a abstração, por outro, o espectador é levado a construir algum grau de reconhecimento diante dessas paisagens por meio da alta definição e da grande dimensão das fotos. Por exemplo, na exibição "Drone: The Automated Image", que ocorreu em 2013 na galeria Darling Foundry em Montreal, Canadá, vê-se uma foto da série "The Fields". Essa exposição coletiva fez parte do festival "Mois de la Photo à Montreal" desse ano, e contou com diversos nomes da fotografia de arte contemporânea, como Pascal Dufaux, Mona Hatoum, Suzy Lake, Thomas Ruff, Penelope Umbrico, Jules Spinatsch, e Michael Wesely. No fundo do galpão, na galeria Darling Foundry, Mishka Henner expõe uma só imagem. Trata-se de uma grande projeção fotográfica.

Pela distância do ângulo vertical, os volumes do humano, da natureza, das arquiteturas e dos artefatos parecem fundir-se na superfície da fotografia, ocasionando a indistinção entre formas e planos. Na projeção fotográfica, visualiza-se apenas um fundo em tons de terra e "sobre ele", aparentemente em primeiro plano, aparecem traços retilíneos. É preciso que o espectador se distancie o máximo da cena retratada para visualizar a extensa área do campo petrolífero e, de longe, a única coisa que se consegue distinguir são linhas de diferentes cores (fig. 2). 


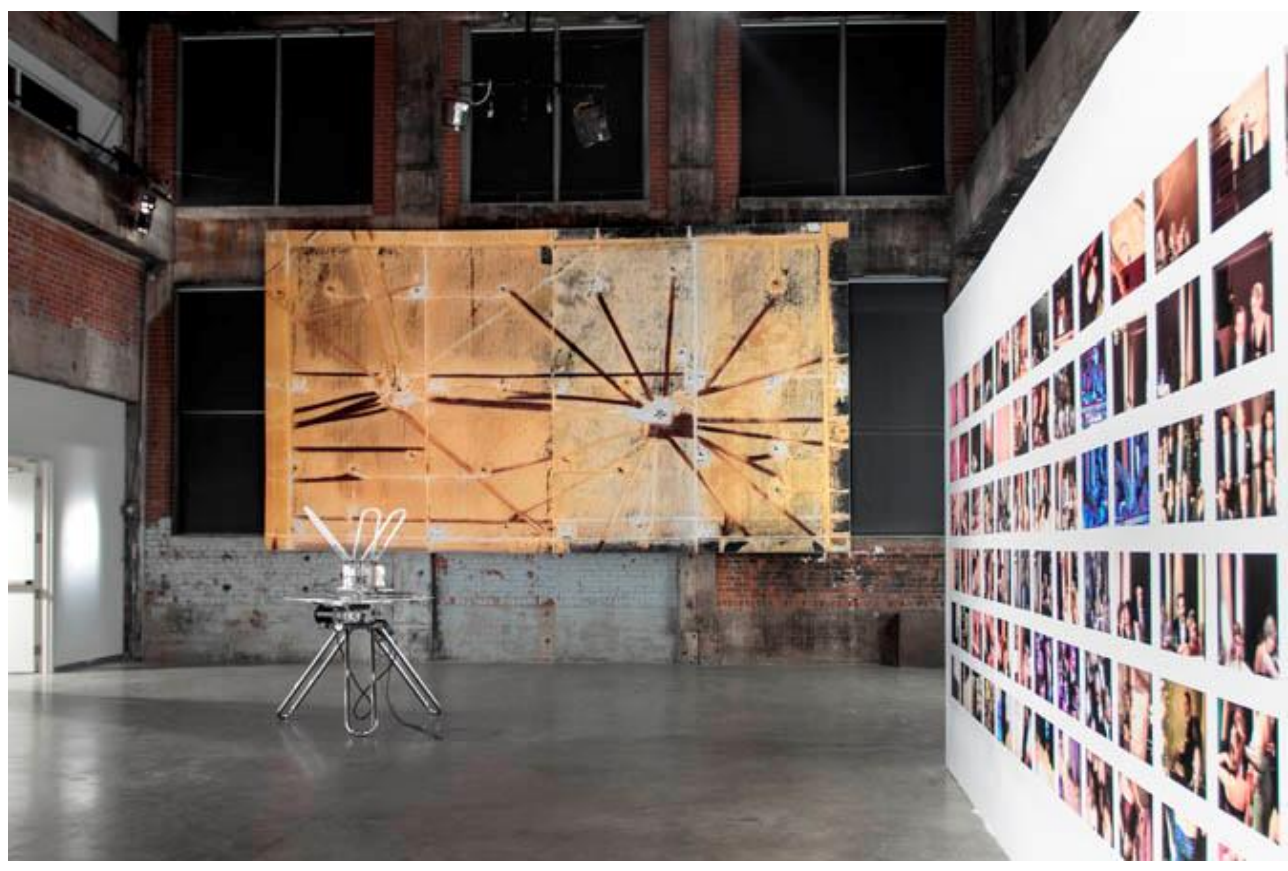

Figura 2 - Levelland Oil Field \#1, Hockley County, Texas (2013) Dimensions variable. Série fotográfica: "Feedlots" - Mishka Henner, 2013. Exibição: Drone: The Automated Image - Galeria Darling Foundry, Montreal, 2013.

No entanto, se o espectador chegar mais perto desta fotografia aérea, ele consegue verificar alguns detalhes da operação industrial petrolífera de Levelland Oil Field, EUA. É possível reconhecer, por exemplo, a aparência de postes de eletricidade e de algumas bombas de feixe, máquinas utilizadas para levantar mecanicamente o petróleo para fora do solo (fig. 3).

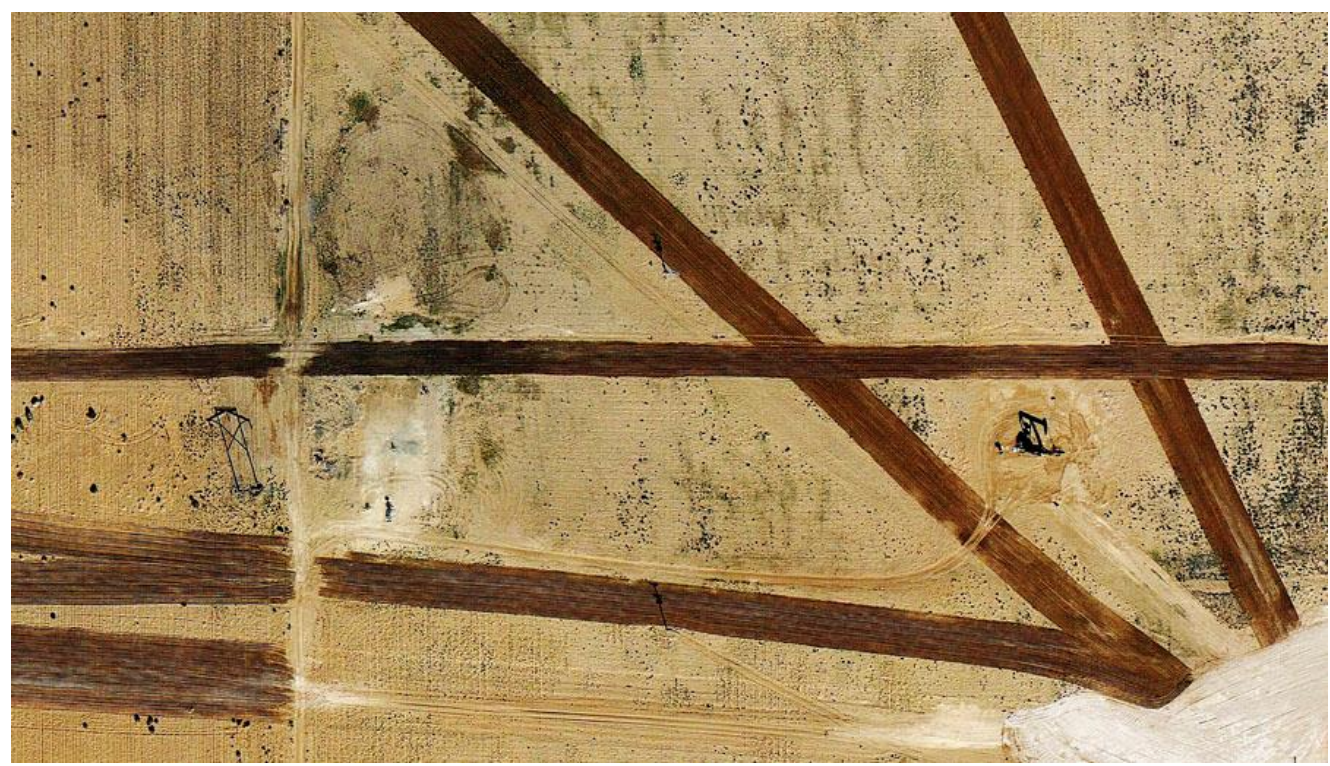

Figura 3 - Levelland Oil Field, Hockley County, Texas (detail). Série fotográfica: "Feedlots" - Mishka Henner, 2013. Exibição: Drone: The Automated Image - Galeria Darling Foundry, Montreal, 2013. 


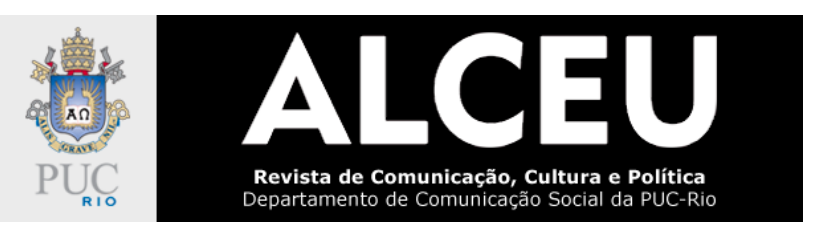

São esses "pequenos" fragmentos fotográficos, como apresentados na figura 3, que Henner captura das plataformas de foto-mapeamento online. No software Google Earth, a tomada aérea que retrata a imensidão desse campo petrolífero não é tão nítida assim. Foi preciso efetuar "zooms" dentro da interface de "foto-mapas" e selecionar recortes fotográficos que foram reunidos (um a um) para compor imagens em alta definição. No seu estúdio em Manchester, Reino Unido, o artista belga compõe fotografias com resolução suficientes para equalizar cores, contrastes, conservando a nitidez para imprimir as fotografias em grandes dimensões. No caso da série "The Fields", Henner se dedica a fabricar pelo menos quatro grandes painéis com extensões que ultrapassam a marca de dois metros de altura e quatro metros de comprimento.

Nessa grande fotografia projetada na parede da galeria Darling Foundry se visualiza, à primeira vista, um todo abstrato. No entanto, se o espectador chegar mais perto, ele poderá verificar o que há "de fato" nessas paisagens (fig. 2 e 3). Está aí a força dessas imagens. As séries "Feedlots" e "The Fields" propõem experiências visuais executadas no jogo entre o distante (a visão aérea e geométrica do todo) e a proximidade (a identificação das minúcias de verossimilhança). Assim, o significado do documento fotográfico é retrabalhado à medida que o espectador se aproxima e se afasta do que vê.

Diria que a expressividade de tais obras está justamente nesta quebra, desarmônica, entre mimese e abstração. Usando de uma mesma linguagem - a fotográfica -, Henner mistura duas lógicas aparentemente opostas. Por um lado, nos ambientes dos museus e das galerias comercias, a boa definição e as amplas dimensões de "Feedlots" e "The Fields" vão dar conta da nitidez documental dessas fotografias de paisagem. Invariavelmente, o espectador sai em busca dos vestígios de verossimilhança: algo inerente às fotografias produzidas como prova documental para fins de geomapeamento. Por outro lado, as mesmas fotos, se observadas ao longe, apresentam uma completa distorção visual do que se vê. Pela mirada aérea, surgem quadrados, retângulos, linhas e manchas na fotografia de paisagem.

Cria-se, por sua vez, uma dinâmica de significação que preza pela descontinuidade, o que, nos termos de Rancière, seria um bom exemplo de "pensatividade da imagem" (RANCIÈRE, 2012). Para o filósofo, quando a imagem suspende quaisquer atividades de transmissão de informação, ou qualquer significado de caráter eminentemente conclusivo, ela se torna um objeto de pensamento capaz de criar uma nova regulagem das fronteiras entre ficção e documento. As "imagens pensativas" são aquelas que propõem essa "abertura" de sentido, em vez da aparência 
imediata, do encadeamento clássico dos fins projetados, das causas e dos efeitos.

Segundo Rancière, tal fenômeno ocorre quando as estratégias artísticas criam "a presença latente de um regime de expressão em outro" (RANCIÈRE, 2012, p. 118). Em suas palavras: "imagens são, exemplarmente, imagens pensativas pela maneira como conjugam dois modos de representação" (RANCIÈRE, 2012, p. 118) ${ }^{4}$. No caso das séries fotográficas analisadas neste paper, estabelece-se um jogo entre formas de expressão antagônicas - a mimese e a abstração , ao passo que o significado dessas fotografias fica "em suspenso": à espera que o espectador decifre o que vê em um processo de experimentação, de várias distâncias, em que o sujeito caminha pelo espaço expositivo e se coloca em relação ao painel fotográfico.

\section{O olhar oblíquo e a atitude experimental na arte}

Mas, é claro, por se tratar de uma representação fotográfica similar a um mapa, operativa, não haveria como se perder à deriva diante dessas imagens. Busca-se, a partir da credibilidade inerente à fotografia produzida para mapeamento geográfico, o que há de "rastro de real" nesses registros fotográficos. De perto ou de longe, as séries estimulam o espectador a decifrar o que são esses espaços de confinamento animal da agropecuária ("Feedlots", 2013) e esses campos de exploração de petróleo ("The Fields", 2013) dos EUA. O que percebo, contudo, é que a relativa geometrização proporcionada pela mirada aérea não ganha significado pela lógica associativa da verossimilhança. Pelo contrário, a abstração visual aparece como efeito de perturbação naquilo que se refere ao teor propriamente representacional da cena.

Não por acaso, Phillipe Dubois entende que a fotografia aérea - nos idos das viagens de balão feitas por Félix Nadar - serviu como forte influência para movimentos pictóricos modernos. São vanguardas que buscavam se distanciar do classicismo, que impôs rigor à representação pictórica da paisagem. Ou seja, a fim de burlar a sistematização visual em perspectiva, em que o pintor encarava o objeto de frente para fabricar a ilusão ótica da representação mimética, artistas do suprematismo russo, como Lissitzky e Malévitch, já em 1914 se inspiravam na distorção visual da mirada aérea de modo a experimentar uma nova plasticidade em suas pinturas. Dubois, por

\footnotetext{
4 "A pensatividade da fotografia poderia então ser definida como esse nó entre várias indeterminações. Poderia ser caracterizada como efeito da circulação entre o motivo, o fotógrafo e nós, do intencional e do não intencional, do sabido e do não sabido, do expresso e do não expresso, do presente e do passado" (RANCIÈRE, 2012, p. 110). "A pensatividade da imagem é então a presença atente de um regime de expressão em outro" (RANCIÈRE, 2012, p. 118).
} 
meio dos escritos da historiadora de arte Rosalind Krauss, poderá elucidar esta questão:

O que impressiona é que, ao contrário das outras fotografias, a vista aérea levanta a questão da interpretação, da leitura. Não se trata simplesmente do fato que, vistos muito de cima, os objetos são difíceis de reconhecer - são efetivamente - mas, mais especialmente do fato de que as dimensões esculturais da realidade são tornadas muito ambíguas: a diferença entre ocos e saliências, convexo e côncavo, apaga-se. A fotografia aérea coloca-nos diante de uma realidade transformada em algo que necessita de uma decodificação... Se toda a fotografia promove e aprofunda nosso fantasma de uma relação direta com o real, a fotografia aérea tende - pelos próprios meios da fotografia - a perfurar a película desse sonho (KRAUSS apud DUBOIS, 2011, p. 262-265).

A fotografia do alto também viria a influenciar o construtivismo da escola de Bahaus, onde Moholy-Nagy (1895-1946) e Rodchenko (1891-1956) fabricavam composições em seus desenhos, pinturas, fotomontagens, esculturas, utilizando ângulos inclinados. Já na arte fotográfica, ambos se tornam conhecidos pelo uso de planos plongée e contra-plongée. O posicionamento da câmera "de baixo para cima" e "de cima para baixo" era o que conferia novas texturas, profundidades e contrastes às fotografias, caracterizando a atitude experimental de suas obras.

Fato é que o "olhar oblíquo" acrescenta perspectivas distorcidas à visão, e fornece instrumentos "às atitudes inaugurais da abstração na arte" (DUBOIS, 2011, p. 265). Em consonância com os argumentos de Rosalind Krauss, Dubois nota que a "inspiração no aéreo" prolonga-se até o Expressionismo Abstrato dos EUA, a exemplo do "action painting" de Jackson Pollock. Pollock, em vez de encarar a pintura de frente, posicionava suas grandes telas no chão. Ele criava um passeio casual por cima dos painéis, enquanto arremessava pingos de tinta em direção ao solo. A flutuação aleatória da "mirada do alto", com seus movimentos multidirecionais, era o dispositivo criado pelo artista para fabricar pinturas com figurações que não podiam ser decifradas.

Mas as ressonâncias entre a fotografia aérea (ou anti-aérea) e o abstracionismo na arte moderna não param por aí. Qualquer cenário, quando fotografado de muito longe, cria estruturas visuais simples, geometrizadas, que haveriam de atingir as vertentes minimalistas da arte: certa investigação que, nos anos 50/60, após o ápice de Pollock nos Estados Unidos, busca brincar com os métodos de produção artística, agindo nos limites das formas e das escalas visuais até convocar opticamente a expressão mínima da representação. O caráter geométrico do minimalismo, de forte influência construtivista ${ }^{5}$, radicaliza o fazer anti-figurativo das Escolas abstratas da Europa - o

\footnotetext{
${ }^{5}$ Herdeira do futurismo italiano e do cubismo francês, a arte construtivista surge no início do século XX e está presente nas obras de grande parte das vanguardas russas. Esse movimento segue o ideal de abstração da arte moderna europeia, e busca romper com a arte clássica que preza pela representação do real e pela a alusão às formas da natureza. De maneira bastante genérica, sua
} 
Futurismo, o Cubismo, a Bauhaus - e recusa, de vez, os atributos ilusionistas e metafóricos de uma obra de arte.

Para despir suas produções artísticas de efeitos decorativos e interpretativos, o minimalismo buscava a concepção simples dos materiais. Na pintura, tratava-se do encontro com formas e contornos elementares, cada vez mais planos e monocromáticos, para mostrar que não há sentidos anteriores à bidimensionalidade da tela. Já o minimalismo escultórico passou a desenvolver objetos com o auxílio de materiais industriais, pré-fabricados, criando estruturas que operam trânsitos conceituais entre o campo da pintura e da escultura. A criação geometrizada de Sol LeWitt, Donald Judd e Robert Moris, por exemplo, passa a questionar estes gêneros tradicionais da arte, quebrando com o julgamento estilístico que separa as formas de criação tridimensional (referente aos volumes escultóricos) da bidimensional (referente à fotografia e à pintura).

De maneira geral, quando reduz a representação à pureza das formas geométricas, a Minimal Art evita que o espectador queira perceber a pintura como algo além do que a materialidade da própria tela. Ao mesmo tempo, o uso da escultura dará volume aos aspectos visuais das geometrias planas (cubos, caixas, esferas, retângulos), evidenciando sentidos que devem ser vividos empiricamente. Em ambos os casos, nega-se uma arte que seja metafórica, interpretativa, portadora de ideias ou emoções prévias. Em vez disso, as formas mínimas (escultóricas, fotográficas e pictóricas) vão prezar pelo encontro corpóreo/material entre espetador-obra. Ou seja, pela vivência da arte relacionada à presença corporal-subjetiva do observador no ambiente expositivo, onde a formalidade do objeto mínimo se encontra (DIDI-HUBERMAN, 2010) ${ }^{6}$.

Nestes termos, a perspectiva aérea e a lógica espacial da verticalidade serão os fatores decisivos para um processo de mudanças na arte. Trata-se de uma desordem em relação ao rigor e ao caráter verossímil da pintura clássica, que, desde o Renascimento, fundamenta-se na mimese

linguagem se caracteriza pela utilização constante de elementos geométricos, cores primárias e fotomontagem. Entre nomes como Aleksandr Rodchenko e Kazimir Malevich - um dos inventores e teóricos da arte não-figurativa -, o construtivismo cria objetos com ênfase no vazio, trabalhando com as formas diante do ambiente em que elas se inserem. É ressaltada, portanto, a presença da matéria na tela, junto à valorização do objeto industrial como forma de dessacralização das estruturas simbólicas da arte.

6 "É fascinante constatar a que ponto a dimensão do corpo humano pôde se achar implicada - e cada vez mais sutilmente - na produção dos artistas americanos desse movimento não obstante explicitamente "geométrico". [...] Sol LeWitt não cessará de implicar a dimensão humana, entre um metro e sessenta e dois metros, em um número bastante considerável de suas obras mais "matemáticas" ou modulares. [...] Ad Reinhardt projetava o quadro de seus sonhos - negro, evidentemente - como "um quadrado (neutro, sem forma) de tela, com cinco pés de largura cinco pés de altura, alto como um homem, largo como os braços abertos de um homem (nem grande, nem pequeno, sem tamanho). Compreende-se na verdade que o "sem tamanho", funciona aí como um operador dúplice de formalidade "específica", geométrica, e de implicação corporal, subjetiva. Ele permite à estatura do objeto pôrse diante de nós com a força visual de uma dimensão que nos olha - nos concerne e, indicialmente, assemelha-se a nós -, ainda que o objeto nada dê a ver além de si, além de sua forma, sua cor, sua materialidade próprias" (DIDI-HUBERMAN, 2010, p. 124125). 


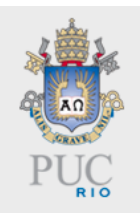

para construir representações do real. Cito as regras da perspectiva, que funcionam pelo ângulo ortogonal, em que os objetos são posicionados precisamente ao nível dos olhos do observador. É pela horizontalidade que esse procedimento técnico funciona. Assim, o pintor fabricava paisagens, acreditando piamente que suas pinturas seriam o perfeito "duplo" da natureza.

Mas, para atingir tamanha perfeição na hora de criar imagens, o homem dependia de uma distância muito bem calculada do objeto a ser representado. Trata-se de um reconhecimento visual que retira toda a instabilidade do meio (sons, cheiros, texturas, vibrações do ambiente), criando pinturas mediante a completa exclusão dos efeitos de "perturbação" do corpo. Em suma, no classicismo, o olho humano não era sinônimo de um órgão que, portanto, se insere em uma corporeidade instável (CRARY, 2012). Pelo contrário, nas divisas epistemológicas da época (sec. XVII e séc. XVIII), a visão era interpretada como um princípio científico de cálculo (refração e reflexão da luz). E o olho era um mecanismo de racionalidade pura, passível de efetuar a leitura verídica do mundo à sua volta.

Contudo, aos poucos, as vertentes modernas das artes criam novas experiências para a pintura, dando lugar à percepção sensorial do artista, à incerteza e à dispersão (séc. XIX). Tremidos, pinceladas rápidas e cortes abruptos na cena retratada irão abalar o equilíbrio fundamental da representação mimética. Chega-se até o momento em que a verticalidade dos ângulos aéreo e anti-aéreo adentram, cada vez mais, a esfera da arte para ressaltar jogos de ocultamento nas imagens pictóricas e fotográficas. A angulação oblíqua age como um verdadeiro "dispositivo teórico" (DUBOIS, 2011) para que a representação atinja uma superfície abstrata.

Toda esta travessia é para perceber que, nas miradas do alto, há uma verdadeira tensão entre o polo mapeável e geolocalizável da fotografia de paisagem, e o polo abstracional. Hoje a fotografia aérea, associada às SIGs e aos usos de GPS, evidencia sua capacidade instrumental para mapear o mundo. Nestas marcas próprias do contemporâneo, utilizam-se softwares como Google Maps (com seus mapas e foto-mapas) indiscriminadamente. Interpretam-se desenhos gráficos, códigos cartográficos e representações fotográficas (verticais e horizontais), a fim de criar caminhos precisos e eficazes pelo globo terrestre. Mas o intenso uso dessas ferramentas de geolocalização urbana, das quais a fotografia aérea é apenas o instrumento de vigia e de reposicionamento do humano nas cidades, não nos deixa visualizar o caráter contingente e codificado da apreensão do mundo a partir de imagens.

Não obstante, nas séries "Feedlots" e "The Fields", a fotografia aérea se mostra como este 
lugar de questionamentos sobre o que é dado a ver. São fotografias de paisagem que se configuram como um dispositivo, como um catalisador de forças históricas, sociais, políticas e estéticas. Isso se dá porque, nessas obras, as vistas de cima se apresentam em sua "condição dupla". A mirada aérea é tanto reduto de uma clareza documental quanto de opacidades. Sua singularidade não é atributo único - relativo à representação do espaço pela verossimilhança -, mas um efeito de sentido produzido no vai e vem do olhar (DIDI-HUBERMAN, 2010)7.

Em outras palavras, ao levar seu corpo para perto dessas grandes fotografias, o espectador experimenta um possível lugar de reconhecimento diante da mirada aérea. De perto, ele vê a figuração sutil de animais, de cercas que dividem os lotes de confinamento de gado, de caminhões, de postes telegráficos e de bombas de extração de petróleo. No entanto, o "todo" informativo dessas fotografias de paisagem só pode ser visto a distância, isto é, quando o espectador se afasta da imagem. A partir daí, o documento se torna opaco. Ele é capaz (até mesmo) de "aparecer" e "desaparecer", diversas vezes, conforme o sujeito caminha pelo espaço expositivo e se relaciona com o painel fotográfico.

Isso acontece porque, de longe, o que o espectador não pode identificar (por verossimilhança) o que há na paisagem. Ele vê apenas cores, manchas, além de uma superfície visual geométrica com traços retilíneos e curvilíneos. Surge, então, uma fotografia de "gestos mínimos", que poderia aludir às correntes minimalistas da arte. Desde a década de 50, a Minimal Art age como procedimento que coloca a experiência física do espectador no centro da questão artística. Outros movimentos recentes, como a arte cinética, a performance, a Body Art, o Side Specific, a Land Art ou as instalações interativas, tratam de encarar a corporeidade do observador e a materialidade do ambiente expositivo como elementos fundamentais para a apreensão estética ${ }^{8}$.

\footnotetext{
7 "Ou seja, uma espécie de formação crítica que, por um lado, perturba o curso normal do rio (eis aí seu aspecto de catástrofe, no sentido morfológico do termo) e, por outro lado, faz ressurgir corpos esquecidos pelo rio ou pela geleira mais acima, corpos que ela "restitui" faz aparecer, torna visíveis de repente, mas momentaneamente: eis aí seu aspecto de choque e de formação, seu poder de morfogênese e de "novidade" sempre inacabada, sempre aberta, como diz tão bem Walter Benjamin. E nesse conjunto de imagens "em via de nascer", Benjamin não vê ainda senão ritmos e conflitos: ou seja, uma verdadeira dialética em obra" (DIDIHUBERMAN, 2010, p. 171).

8 Este reconhecimento da visão como algo "modulado pelos fenômenos do corpo" (percepção incorporada, por assim dizer) esteve em ascensão desde o século XIX. Se, por um lado, o realismo e o positivismo estiveram presentes nas correntes da cultura científica e popular oitocentista, ratificando um olhar "racionalizado" para as coisas do mundo - vide o surgimento dos museus de cera (a exemplo do Musée Grévin) e das curiosas "salles d'expositions" do necrotério de Paris -, por outro, certos brinquedos ópticos, assim como os quadros tridimensionais e o panorama, começavam a associar a visão à instabilidade corpórea do observador. Um "momento em que o visível se abriga em outro aparato, no interior da fisiologia e da temporalidade instáveis do corpo humano" (CRARY, 2012, p. 74). Os panoramas, desenvolvidos no final do século XVIII, configuram-se como a primeira tentativa de simular uma realidade, ou seja, "fazer parecer real o que não é". Este dispositivo era composto por uma pintura circular, além de uma
} 
No minimalismo, surge uma arte que visa "nada informar". Não é necessário interpretar "nada além" do que a própria expressão mínima das formas geométricas. São obras de arte que dão ênfase a um "corpo a corpo" entre o espectador e a tela da pintura; ou entre a tridimensionalidade da escultura. Uma associação entre visão e experiência corporal, expressa desde a modernidade no século XIX, quando a percepção do sujeito - pelo crescente estímulo sensório-motor dos corpos nas cidades - parecia estar cada vez mais suscetível às modelizações de um corpo fisiológico, e de uma conjuntura sociocultural que o interpele (CRARY, 2012; BENJAMIN, 1994) ${ }^{9}$.

Assim, quando apreciadas de longe, as fotografias de paisagem de "Feedlots" e "The Fields" mostram sua formalidade geométrica. São paisagens que exploram o reducionismo das formas, pondo em tensão o campo propriamente tradicional da pintura e da fotografia. Cito o culto dominante da representação mimética, em que a imagem - pelo "efeito-real" das regras da perspectiva - parece estabilizar muito bem a recepção figurativa da paisagem. No classicismo, a documentação do "real" visa identificar plenamente todos os objetos e seres que compõem a tela da pintura. No lugar disso, o minimalismo advoga a favor de uma ruptura radical com a arte mimética. A redução visual das formas pictóricas e escultóricas busca estabelecer uma relação conflituosa entre sujeito-obra: dado pelo ordenamento corpóreo do sujeito junto à "simplicidade" material do que ele vê.

\section{Considerações finais}

Em suma, nesses trabalhos fotográficos, Mishka Henner coloca o espectador em meio a um conflito interpretativo, em meio a uma relação entre "duas distâncias" (DIDI-HUBERMAN, 2010) ${ }^{10}$.

estrutura especialmente planejada para possibilitar a criação de um ambiente simulado. No entanto, nos panoramas, o efeito-real dependia da completa inserção corpórea do indivíduo dentro do mecanismo. Assim, diferentemente do regime óptico clássico - em que o sujeito recebia passivamente a imagem "verdadeira" do mundo (a paisagem representada na tela pictórica) -, o panorama admite que o corpo humano é capaz de modular e até mesmo intensificar o efeito ilusório criado por painéis circulares de pintura.

${ }^{9}$ Frente ao crescimento e à industrialização das cidades modernas, a participação do sujeito se tornava fundamental como parte do processo perceptivo. Seja para atravessar ruas movimentadas ou utilizar transportes mecanizados, não era mais possível olhar o mundo ignorando as manifestações ao redor, que influem diretamente sobre o corpo, os sentidos, o cérebro. "O observador teve de operar cada vez mais em espaços urbanos fragmentados e desconhecidos, nos deslocamentos perceptivos e temporais das viagens de trem, do telégrafo, da produção industrial e dos fluxos de informação tipográfica e visual" (CRARY, 2012, p. 20). Ou seja, em tempos de circulação, velocidade, multidão e choque (BENJAMIN, 1994), perceber a realidade moderna era literalmente "incorporar" a visão.

10 "Falar de imagens dialéticas é no mínimo lançar uma ponte entre a dupla distância dos sentidos (os sentidos sensoriais, o ótico e o tátil, no caso) e a dos sentidos (os sentidos semióticos, com seus equívocos, seus espaçamentos próprios). Ora, essa ponte, ou ligação, não é na imagem nem logicamente derivada, nem ontologicamente secundária, nem cronologicamente posterior: ela é 
De um lado, a possibilidade do encontro verossímil com a fotografia de paisagem, de outro, a vivência sensorial (ótica e tátil) das formas geométricas. Nas fotografias de Henner, esses dois polos parecem "servir-se" um do outro. Assim, o artista encontra uma forma particular de expandir o campo do tradicionalmente entendido como pictórico e fotográfico.

As séries "Feedlots" e "The Fields", apesar de manterem o teor documental da vista aérea, têm forte interferência dos modelos visuais já estabelecidos nas artes de vanguardas. Nas análises de alguns trabalhos artísticos de Mishka Henner, busquei "emparelhar" as referidas séries fotográficas com as normas estilísticas da pintura clássica e com as vertentes "abstratas" da arte. Busca-se, nesse sentido, chamar a atenção para uma produção artística que dialoga com os usos massivos da fotografia no ambiente online, e faz isso a partir de um forte comprometimento em "movimentar" as hierarquias da arte - jogando simultaneamente com vários sistemas de signos a fim de romper com categorias estanques e com quaisquer parâmetros rígidos que estabilizem os sentidos da fotografia contemporânea.

Grécia Falcão

Professora na Universidade Lusíada de Lisboa

Doutora em Comunicação / UERJ ORCID: https://orcid.org/0000-0002-7547-0870

E-mail: falcaogrecia@gmail.com

Recebido em: 8 de abril de 2020 .

Aprovado em: 28 de maio de 2020.

originária, muito simplesmente - ela também. [...] E a relação dessas duas distâncias já desdobradas, a relação dessas duas obscuridades constitui a imagem - que não é pura sensorialidade nem pura memoração - exatamente o que devemos chamar de aura. Teríamos vontade de dizer, portanto, que a dupla distância é aqui originária, e que a imagem é originalmente dialética, crítica. Mas é preciso precaver-se de toda acepção trivial quanto a essa "origem": só a nomeio assim porque ela é já desdobrada, justamente, ou différante. Só a nomeio assim porque ela intervém em Walter Benjamin a título de conceito ele próprio dialético e crítico" (DIDIHUBERMAN, 2010, p. 169-170). 


\section{ALCEU

Referências

BENJAMIN, Walter. Obras escolhidas; vol.1. Magia, técnica, arte e política: ensaios sobre literatura e história da cultura, Brasiliense, São Paulo, 1994.

CAUQUELIN, Anne. A invenção da paisagem. São Paulo: Martins Fontes, 2007.

CRARY, Jonathan. Técnicas do observador - Visão e modernidade no século XIX. Rio de Janeiro: Contraponto, 2012.

Suspensões da Percepção: Atenção, Espetáculo e Cultura Moderna. Editora: Cosac Naify, 2013.

DAVIES, Lucy. (2014) Mishka Henner: a Duchamp for our times. In: The Telegraph. Disponível online: http://www.telegraph.co.uk/culture/photography/10813540/Mishka-Henner-a-Duchamp-for-our-times.html.

Acesso em: 15 set. 2017.

DIDI-HUBERMAN, Georges. O que vemos, o que nos olha. Ed. 34, São Paulo, 2010.

Sobrevivência dos Vagalumes. UFMG, Belo Horizonte, 2011.

. Imagens apesar de tudo. Trad. Vanessa Brito e João Pedro Cachopo. Lisboa: KYM, 2012.

Diante do tempo. Belo Horizonte: Ed. UFMG, 2015.

DUBOIS, Philippe. O ato fotográfico e outros ensaios. São Paulo: Papirus, 1994.

GEAR, Elizabeth Sulis. (2016) Horrific Satellite Images of Texas Feedlots. In: Feature Shoot. Disponível online: https://www.featureshoot.com/2016/08/horrific-satellite-images-of-texas-feedlots/ Acesso em: 10 de out. 2017.

RANCIĖRE, Jacques. A partilha do sensível. Estética e política. São Paulo: Ed. 34, 2005.

. O espectador emancipado. São Paulo. Martins Fontes, 2012.

ONISH, Norimitsu. (2014) A California Oil Field Yields Another Prized Commodity. In: New York Times. Disponível online: https://www.nytimes.com/2014/07/08/us/california-drought-chevron-oil-field-waterirrigation. html?rref=collection\%2Fbyline\%2Fnorimitsuonishi\&action=click\&contentCollection=undefined\&reg ion=stream\&module=stream unit\&version=latest\&contentPlacement=148\&pgty._Acesso em: 01 fev. 2018.

\section{Resumo}

Os sistemas de mapeamento geográfico do Google (Google Maps) e demais softwares acoplados ao serviço (Google Earth e Google Street View) utilizam o registro fotográfico como principal 


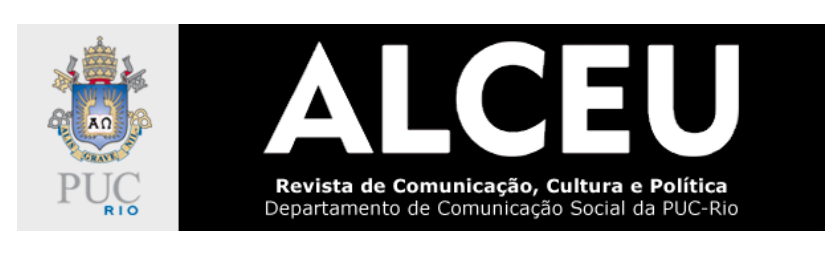

ferramenta de documentação e de mapeamento da geografia terrestre. Para a ciência cartográfica, a fotografia aérea é uma importante ferramenta de análise e de gerenciamento de informações geográficas, sendo a técnica ideal para a criação de uma narrativa visual, que preza pela verossimilhança, ou seja: pela "melhor" e "mais fiel" representação possível do espaço. Por outro lado, neste paper, gostaria de problematizar o sentido comunicacional dos registros fotográficos fornecidos pelos mapas Google a partir da análise de duas séries fotográficas criadas por Mishka Henner: artista belga conhecido por utilizar, como fonte de pesquisa para suas obras, arquivos fotográficos disponíveis online. Ao que parece, as estratégias de apropriação, produção e montagem expositiva operacionalizadas pelo artista são capazes de multiplicar as formas de comunicação das imagens fotográficas, e de "fazer variar" o sentido deste conjunto de "fotografias-mapa" geradas pela empresa Google.

Palavras-chave: Google Maps. Tecnologias da Comunicação. Fotografia de Paisagem. Arte Contemporânea.

\section{Abstract}

Google's geographic mapping systems (Google Maps) and other service-coupled software (Google Earth and Google Street View) use photographic registration as the primary documentation and mapping tool for terrestrial geography. For cartographic science, aerial photography is an important tool for the analysis and management of geographic information, and is the ideal technique for creating a visual narrative that values likelihood, that is, for the "best" and "most faithful" representation. possible from space. On the other hand, in this paper, I would like to discuss the communicational meaning of the photographic records provided by Google maps from the analysis of two photographic series created by Mishka Henner: a Belgian artist known for using photographic archives as a research source for his works. available online. Apparently, the strategies of appropriation, production and exhibition montage operationalized by the artist are able to multiply the forms of communication of photographic images, and to "vary" the meaning of this set of "map photographs" generated by the company Google.

Keywords: Google Maps. Communication Technologies. Landscape photography. Contemporary Art.

\section{Resumen}

Los sistemas de mapeo geográfico de Google (Google Maps) y otro software acoplado a servicios (Google Earth y Google Street View) usan el registro fotográfico como la principal herramienta de documentación y mapeo para la geografía terrestre. Para la ciencia cartográfica, la fotografía aérea es una herramienta importante para el análisis y la gestión de la información geográfica, y es la técnica ideal para crear una narrativa visual que valore la probabilidad, es decir, para la representación "mejor" y "más fiel". posible desde el espacio. Por otro lado, en este artículo, me gustaría discutir el significado comunicativo de los registros fotográficos proporcionados por los mapas de Google a partir del análisis de dos series fotográficas creadas por Mishka Henner: un artista belga conocido por usar archivos fotográficos como fuente de investigación para sus obras. Disponible en línea. Aparentemente, las estrategias de apropiación, producción y montaje de exhibición operacionalizadas por el artista pueden multiplicar las formas de comunicación de las imágenes fotográficas y "variar" el significado de este conjunto de "fotografías de mapas" generadas por la empresa Google.

Palabras clave: Google Maps. Tecnologías de Comunicación;. Fotografía de paisaje. Arte Contemporaneo. 